\title{
GCU
}

Glasgow Caledonian

University

University for the Common Good

\section{An online module evaluation of the role and effectiveness of wikis in fostering collaborative practice skills in interprofessional education: a short report}

Burns, Lindsey; McDermott, Jamie; Mulholland, Rachel; Blumenthal, Sharron; McLarnon, Nichola

Published in:

Journal of Interprofessional Care

DOI:

10.1080/13561820.2020.1806217

Publication date:

2021

Document Version

Author accepted manuscript

Link to publication in ResearchOnline

Citation for published version (Harvard):

Burns, L, McDermott, J, Mulholland, R, Blumenthal, S \& McLarnon, N 2021, 'An online module evaluation of the role and effectiveness of wikis in fostering collaborative practice skills in interprofessional education: a short report', Journal of Interprofessional Care, vol. 35, no. 5, pp. 791-793.

https://doi.org/10.1080/13561820.2020.1806217

\section{General rights}

Copyright and moral rights for the publications made accessible in the public portal are retained by the authors and/or other copyright owners and it is a condition of accessing publications that users recognise and abide by the legal requirements associated with these rights.

Take down policy

If you believe that this document breaches copyright please view our takedown policy at https://edshare.gcu.ac.uk/id/eprint/5179 for details

of how to contact us. 


\section{An Online Module Evaluation of The Role and Effectiveness of Wikis in Fostering Collaborative Practice Skills in Interprofessional}

\section{Education}

Burns, Lindseya*, McDermott, Jamie ${ }^{\mathrm{b}}$, Mulholland, Rachelc, Blumenthal, Sharron ${ }^{\mathrm{d}}$ and McLarnon, Nichola ${ }^{\mathrm{e}}$

${ }^{a * D e p a r t m e n t ~ o f ~ P s y c h o l o g y, ~ G l a s g o w ~ C a l e d o n i a n ~ U n i v e r s i t y, ~ G l a s g o w, ~ S c o t l a n d ; ~}$

@lburnspsych1

${ }^{b}$ Department of Occupational Therapy, Human Nutrition and Dietetics, Glasgow

Caledonian University, Glasgow, Scotland; @1JamieMcDermott

${ }^{c}$ Department of Psychology, Glasgow Caledonian University, Glasgow, Scotland;

${ }^{d}$ Department of Physiotherapy School of Health and Life Sciences, Glasgow

Caledonian University, Glasgow, Scotland; @Sbl2Sharron

${ }^{e}$ Associate Dean Learning Teaching and Quality, School of Health and Life Sciences, Glasgow Caledonian University, Glasgow, Scotland.

Dr Lindsey Burns, Department of Psychology, Glasgow Caledonian University, Cowcaddens Road, Glasgow, G4 0BA.

Lindsey.Burns@gcu.ac.uk 


\title{
An Online Module Evaluation of The Role and Effectiveness of Wikis in Fostering Collaborative Practice Skills in Interprofessional
}

\section{Education}

\begin{abstract}
:
This short report focuses on student feedback relating to the use of online group wikis as a means of a summative assessment intended to foster skills in collaborative practice for a large interprofessional education (IPE) module. Electronic feedback from $112(72.2 \%$ response rate) students suggested wikis were a key area of the module. Open text comments relating to the wikis were extracted and categorised initially as positive or negative with sub-themes then being identified within these two broad categories. Findings showed that students valued the experience of a novel type of assessment but felt the amount of work required was too great. We concluded that digital capabilities need to be part of the developmental skill set of students and this raises important issues for further research to consider whether wikis themselves as a computer supported collaborative learning tool are appropriate for large scale IPE delivery.
\end{abstract}

Keywords: Wiki; summative assessment; interprofessional education; interprofessional collaboration; collaborative practice.

\section{Introduction:}

Interprofessional education has been part of our curriculum since 2004. We have developed our provision and curriculum around this important topic and introduced an IPE framework that now offers a suite of modules to upwards of 4000 students at a time. Following an exposure, immersion and mastery model (Charles, Bainbridge and Gilbert, 2010) we have a core module at each of the four levels of our four year undergraduate programmes. At level 2 (year two) this module is "Working in 
Interprofessional Teams" or "WIT" a module which aims to use relevant psychological and sociological theory to engage students with the concept of communities, asset based approaches to health, and their impact upon health and well-being. This trimester long credit bearing module ran for the first time with a small cohort $(\mathrm{n}=155)$ allowing an exploration of the development of collaborative practice skills through the use of an online Wiki.

A wiki is a collaborative online space where information is presented, edited and agreed by those creating the wiki in a style that is open, accessible and responsive to change (Morley, 2012). Wikis have attracted interest in higher education environments because they facilitate the collaborative processes required for developing student group assignments (Zitzelsberger et al. 2015).

The use of Social Media in IPE has been advocated as a potential method to overcome some of the challenges to implementing IPE activities owing to schedule and location conflicts (Rankin et al.2019), and thus a group wiki was deemed pedagogically appropriate.

Our aim was that students would learn about team functioning, the necessity for each of their professions to be able to work as part of an interprofessional team, and the benefits that this can bring to both individual practitioners and clients or patients (Reeves et al. 2012). This would start to bridge the gap between education and practice, fostering the development of virtual team skills increasingly desired in the health and social care workforce and those of collaborative practice (Umoren et al. 2018). Students worked in interprofessional teams to identify an issue impacting upon a local community, and to provide a research-based group wiki to deliver their results. 


\section{Methods:}

Students $(\mathrm{n}=155)$ from Occupational Therapy, Physiotherapy, Operating Department Practice, Radiotherapy and Oncology, and Podiatry were enrolled in the module and were placed into groups of approximately 5 students during week 1 of the twelve-week trimester. At least three disciplines were represented in each group. Each group had online access to a templated wiki. There were three separate submission points during the 12 week long trimester and running alongside this assessment was a series of lectures and class tutorials where the topics being asked about in the wiki were covered in depth.

Feedback on each wiki submission was given electronically to each group prior to the next submission, allowing a formative aspect to the summative assessment. Following the final wiki submission, feedback from the students on their experiences of the module was collated using EvaSys, a customisable evaluation survey that was being piloted by the University. Students received an individual email and followed a link within that to the survey. This allowed responses to be tracked, so those who didn't complete the survey received a reminder email. All responses were anonymous, and feedback was collected over a two week period. The evaluation asked questions about four key areas: students overall satisfaction with the module; the teaching; the assessment and feedback; and academic support on the module. Finally, there were open comments boxes one asking for positive and one negative aspects of the module. The focus of this short report is that relating to assessment and feedback and specifically that gained through the open text comments in relation to the use of wikis.

\section{Results:}

Feedback was provided by 112 students $(72.2 \%)$ 
Overall the ratings for assessment and feedback were positive, with no ratings below the neutral mid-way point.

Initial examination of the open text comments showed a large proportion of these were related specifically to the wiki. In total 79 students gave statements on positive aspects of the module and 89 on negative aspects. Within these $25(32 \%)$ of the 79 positive comments and $45(51 \%)$ of the 89 negative comments related to the wiki assessment. This suggested to us that Wikis were a key area and we proceeded to extract those comments for further investigation. A basic analysis of the comments was undertaken by two of the authors independently with comments being placed either in a negative or positive category. Following this a second step of analysis was conducted where subthemes within the two main categories were identified. This second step was performed initially by the first author and then verified by the second author. These are shown in the table below

Insert Table 1 here

\section{Discussion and Conclusion:}

The module team hoped the wiki would provide an innovative assessment allowing students to work around the issue of meeting face to face while still fostering the development of collaborative practice skills (Djukic et al. 2015). However, students' experience didn't always match up to our expectations. They did see the value of the wiki as a form of assessment and liked that it was different from assessment methods on other modules; however, some felt the use of a new technology was too much and experienced frustration as a result of the platform itself (Hadjerrouit, 2011). Students 
also indicated a desire for face to face meetings. The project has identified the importance and necessity of ensuring the acceptability of new online learning and teaching methods amongst students. Equally, it is important to ensure that students have the necessary digital capabilities, both in terms of skill and equipment, to engage with new online methods.

Changes were made to the module on the basis of this feedback. The wiki now has only one submission and more extensive information is provided on how to use the wiki and on the provision of digital skills for interprofessional learning. In conclusion we believe the wiki is a valuable learning and assessment tool. We also believe it creates opportunity for students from different professions to learn with, from and about each other whilst also enhancing digital skills capabilities. This is something we will explore further and seems of particular use to others due to the current global pandemic with the need for online delivery of educational materials and assessments.

\section{References:}

Charles, G., Bainbridge, L., \& Gilbert, J. (2010). The University of British Columbia model of interprofessional education. Journal of interprofessional care, 24(1), 9-18. 
Djukic, M., Adams, J., Fulmer, T., Szyld, D., Lee, S., Oh, S., \& Triola, M. (2015). ELearning with virtual teammates: A novel approach to interprofessional education. Journal of Interprofessional Care, 29(5), 476-482. https://doi.org/10.3109/13561820.2015.1030068

Hadjerrouit, S. (2014). Wiki as a collaborative writing tool in teacher education: Evaluation and suggestions for effective use. Computers in Human Behavior, 32, 301-312.

Morley., D, (2012) Enhancing networking and proactive learning skills in the first year university experience through the use of wikis. Nurse Education Today, 32 , (3), 261-266.

https:/doi.org/10.1016/j.nedt.2011.03.007

Reeves, S., Tassone, M., Parker, K., Wagner, S. J., \& Simmons, B. (2012). Interprofessional education: An overview of key developments in the past three decades. Work, 41(3), 233-245.

Rankin, A., Truskey, M., \& Chisolm, M.S (2019)

The Use of Social Media in Interprofessional Education: Systematic Review JMIR Medical Education. 5(1):e1132

Umoren, R., Scott, P., Sweigart, L., Gossett, E., Hodson-Carlton, K., Johnson, M., ... Das, R. (2018). A comparison of teamwork attitude changes with virtual TeamSTEPPS ${ }^{\circledR}$ simulations in health professional students. Journal of Interprofessional Education \& Practice, 10(C), 51-55. https://doi.org/10.1016/j.xjep.2017.12.001

Zitzelsberger, H., Campbell, K., Service, D., \& Sanchez, O. (2015).

Using Wikis to Stimulate Collaborative Learning in Two Online Health Sciences Courses Journal of Nursing Education. 54(6):352355https://doi.org/10.3928/01484834-20150515-08 
Table 1: Quote exemplars from student feedback 


\begin{tabular}{|c|c|}
\hline $\begin{array}{l}\text { 1. The students' preference for a different } \\
\text { type of assessment being met through the } \\
\text { wiki }\end{array}$ & $\begin{array}{l}\text { "Enjoyed working on the wiki assessment and learning about } \\
\text { a new community programme and working with other } \\
\text { professionals in healthcare" }\end{array}$ \\
\hline & $\begin{array}{l}\text { "The nature of the assessment (an online wiki) is great and is } \\
\text { preferred to that of previous modules. I feel that some } \\
\text { students have been able to produce better quality work as they } \\
\text { have been able to complete the required tasks in their own } \\
\text { time and not have to worry about presenting in-front of the } \\
\text { class" }\end{array}$ \\
\hline & $\begin{array}{l}\text { "Working on the wiki was different from the usual way of } \\
\text { assessments and was more interesting" }\end{array}$ \\
\hline \multirow[t]{2}{*}{$\begin{array}{l}\text { 2. The benefits of working with students } \\
\text { from different interprofessional disciplines. }\end{array}$} & $\begin{array}{l}\text { "Helpful for learning about other AHP and getting us all to } \\
\text { work together" }\end{array}$ \\
\hline & $\begin{array}{l}\text { "Getting to work with other professions and how we as a team } \\
\text { can work effectively together" }\end{array}$ \\
\hline Negative Aspects of the Wiki: & Examples: \\
\hline \multirow[t]{2}{*}{$\begin{array}{l}\text { 1. The module was over assessed with three } \\
\text { wiki submissions }\end{array}$} & "3 parts of the wiki - it is too much" \\
\hline & "definitely over assessed 3 wikis is loads of work. \\
\hline 2. Problems with the platform & $\begin{array}{l}\text { "Although the wiki was fun it was sometimes difficult to } \\
\text { work with" }\end{array}$ \\
\hline & $\begin{array}{l}\text { "The system used to create wiki's does not run smoothly on } \\
\text { some computers and can be frustrating at times" }\end{array}$ \\
\hline
\end{tabular}




\begin{tabular}{|l|l|}
\hline $\begin{array}{l}\text { 3. Students did not like the wiki or did not } \\
\text { like group work. }\end{array}$ & $\begin{array}{l}\text { "the wiki's why learn some new program when it would } \\
\text { have been a lot easier to use a technology we had already } \\
\text { mastered" }\end{array}$ \\
\hline & $\begin{array}{l}\text { "I really did not enjoy the wiki aspect of the module. I felt } \\
\text { that as this was the first time we had been introduced to } \\
\text { wikis it was rather overwhelming to know that such a large } \\
\text { part of our grade would be coming from this form of } \\
\text { assessment" }\end{array}$ \\
\hline
\end{tabular}

